\title{
策ettromian 迎ectures
}

on

\section{THE SURGICAL DISEASES CHILDREN.}

DLLIVERED BEFORE THE MEDICAL SOCIETY OF LONDON.

BY

THOMAS BRYANT, F.R.C.S., assistant-SURGEON to GUY'S hospital.

LECTURE I.

Mr. President and Gentuenen,-The diseases of children have from an early period of the practice of the healing art monopolised a considerable portion of the attention of the practitioner; although it has been reserved for men of the present century to enter more scientifically into the subject, to search out the peculiarities of the child's diseases, and to elucidate the differences which are to be observed between the affections of early and adult life. Hence it is only within the last few years that the diseases of children have been shaped into a speciality, and have exclusively occupied the attention of some of the leading inembers of our profession.

It can be scarcely doubted that we are indebted to this sudden increase in our knowledge of such an important branch of medical and surgical study, to the rapid advance of physiology as a science; for how could men comprehend the differences between the diseases of childhood and of the adult, when they were comparatively ignorant of the processes by which health was maintained, and more particularly of the means by which the development and growth of the infant structure passed on to the perfection of mature life?

To this advarce in physiological study may be fairly attributed our more correct knowledge of pathology; and it is upon this solid and sound basis that our present improved acquaintance with the diseases of early life has been unquestionably reared.

The Council of this old and honoured Society, recognising the importance of this subject, have been led to believe that the interest of its members might be promoted and the profession benefited by having their attention drawn from the broad field of general medicine and surgery to the comparatively small one occupied by that of the diseases of children : and, on the strength of this belief, have been induced to abandon the custom by which they have been hitherto bound, and have defined the subjects for their Lettsomian Lectures before nominating the lecturers who were to be selected for their delivery. In carrying out these intentions, the Council have mominated me to deliver their surgical course; and they will not, therefore, be surprised that I should confine my attention exclusively to the surgical aspect of the subject; they well knew also that my attention had not been more particularly devoted to the diseases of early life than to those of the adult; and I therefore take it that they believed the subject would be the most advantageously illustrated by one whose experience embraces the broad field of surgery, and had not been narrowed by the contracted view which is too often engendered by the special practice of any one class of medical or surgical diseases.

I propose, therefore, in carrying out these assumed intentions of your executive body, to occupy your attention during these three lectures by more particularly pointing out the differences which are to be found between the surgical affections of early and adult life. Having, in the first place, glanced at the differences in the physiology between the two classes, and shown how the pathological processes are modified by such conditions, I shall, lastly, endeavour to point out in what way this knowledge should influence our practice both in the treatment of disease and injury. I shall review the subject systematically, taking up the various systems in rotation, after having dwelt, as far as time will allow, upon some of the special surgical affections of early life.

\section{The differences between the Physiology of} The AdUlt and OF THE Child.

I doubt whether I shall be deemed to be departing far from the truth when $I$ assume it to be a physiological fact, which all men readily admit: That in adult life the vital forces, started, supported, and maintained by the nervous, respiratory, circulatory, and glandular systems, are mainly employed for the simple preservation of man's physical structure; or, in other words, for, the maintenance of what las already attained its perfect growth and complete development. I do not deny that these forces may exist for other subsidiary, or perhaps higher purposes; but it is for the maintenance of the body that they are doubtless principally concerned; and, for the present, this fact alone is one which I would have you bear continually in mind during the consideration of the subject upon which we are now engaged.

The second point, which I would also wish to be impressed with equal force upon your minds, may be thus aphoristically expressed; and I believe that it will be accepted as readily as the last: That in infant and child life, the vital forces, originated, supported, and maintained by the nervous, respiratory, circulatory, and glandular systems, are mainly directed for the purposes of growth and develop. ment of the being's physical structure; a portion only of their power being employed for its preservation or maintenance.

The grand distinction between the two classes rests upon the fact, that in the child the vital forces are directed for its growth and development, whilst in the adult they are mainly employed for the maintenance of man's physical structure.

Under these apparently diverse physiological conditions, it can be no subject of surprise that there should exist a material difference between the diseases of early and of adult life ; and that the pathological processes should be somewhat modified by the physiological principles. For in man's high nature, in which the physical forces are so wonderfully correlated, the influence of growth and development upon diseased processes are too great to be passed over without aitention; for it is to the abnormal direction given to these natural processes that most of the special affections of infancy are to be attri- 
buted ; and in no single morbid action in young life can their influence even for one moment be disregarderl. For, although the forces which are employed in the building up of the body, and in maintaining it when completed, may be mere different expressions of the same power directed in different directions, growth, development, and maintenance are so distinct in their several natures, and so uniform in their ends, that it might be excusable if, for a moment only, we were to regard them as originating from independent sources, and to be expressions of distinct powers. Daily practice proves to us that the growth of a part may go on in all its completeness, whilst its development may be arrested, or progress in an abnormal direction; or we may wituess the development progressing in its normal channel, with growth showing itself either in excess or in diminished force ; and yet during this time the maintenance of the whole body may be preserved. All malformations are, therefore, but results of some defective power either in the process of growth or of development, or of hoth; and they are always to be explained by the preponderance, diminution, or abnormal manifestation of one or of the other. Harelip, fissured palate, monsters, cerebral tumours, and spina bifida, etc., are to be explained by some defect in the natural development of the child ; its growth and maintenance being, in the majority of instances, perfect of its kind; whilst instances may presently have to be recorded in which growth alone has proved defective, development remaining perfect.

\section{Tine Greater Activity of Infaytule Diseases.}

We will now pass on to the consideration of another distinctive feature of infantile diseases, which characterises one and all; and that is, their greater activity when compared with those of adult life.

This pathological fact is doubtless to be explained by another physiological truth, which is applicable to adult as well as to child life, although it may be more particularly exemplified in the last :

That the activity of disease appears to be in direct proportion to the activity of the vital processes going on in a part; that in highly vascular organs, morbid processes progress more rapidly than they do in others less favoured; and that in proportion to the extent of action going on in a part will the development of morbid phenomena be manifested, when once originated.

In early life, therefore, the well known activity of the vital processes in all the organs renders them particularly prone to morbid phenomena ; and those parts in which development is progressing the most actively are the most liable to become the seat of morbid action.

Again: During derelopment and growth, cell-life is necessarily active; for it is needless to dwell upon the fact that it is through such cell-growth that all development and increase must be carried out. In morbid actions, therefore, when once originated, a like cell-growth and multiplication is to be observed; and this point is well exemplified in the case of tumours. For such tumours, when once developed in children, are generally of rapid growth; and, whether simple or malignant, their peculiar characteristic is cell-structure: the simple tumours being a rapid repetition of their original elements; and the malignant consisting almost entirely of a cellnature, being invariably of the so-called medullary character; the vital processes manifesting their power by the rapid growth and repetition of the original cell, which had gone astray and become a prodigal, in lieu of developing into a structure of a more perfectly organised nature. Their growth also is generally rapid, being in accordance with the activity of the other functions; healthy and diseased processes having, in this respect, a strong ana$\log y$.

As I proceed with my subject, I shall have the pleasure of illustrating more fully the truth of these remarks; and I propose, therefore, to pass on to discuss more particularly the specialities of the surgical diseases of children, commencing with such as are to be explained by some defective power either in the growth or development of the infant structure; the defects which are to be found in the digestive system having our primary attention. [To be continued.]

\section{过martis}

ox

\section{DR. CHAMBERS'S ASSERTION THAT DISEASE IS IN ALL CASES A DEFICIENCY OF ACTION. \\ BY}

\section{LIONEL S. BEALE, M.B., F.R.S.}

No wonder Dr. Chambers is alarmed. I spoke of weakening the life of the cancer, not the life of the patient! He says : "Of course, he (Dr. Beale) goes on to infer that the aim and intention of a physician should often be to weaken life"; and, towards the close of his spirited remarks, observes with seriousness: "This is not a mere question of verbal criticism ; it is a matter of life and death to our patients". Let me at once dispel his fears. The patients are safe. My colleagues, surgical as well as medical, are, with myself and a very large majority of British practitioners, fully conversant with the necessity of giving support to patients suffering from exhausting diseases; and the pupils have daily opportunities of observing the advantageous effects of the practice.

I cannot but think my friend's fears with regard to the use of lowering treatment by practitioners in the present day are almost groundless. I would ask him if, in his experience, he knows of a single case of "pneumonic consolidation" treated by a British practitioner, during the last ten years, by "weakening life by bleeding coup sur coup, or by starvation"? The praciice undoubtedly existed in days gone by ; but, as a practice, it is now most assuredly extinct.

Dr. Chambers fears I am tending towards the condition of mind of "a certain strong-minded and strong-limbed young lady", who had no pity for people who were "out of health" or "ill", but only for those who suffered from definite disease like apoplexy or measles; and asks me if I have "never hcard of people being ill of the doctor". The tendencies of my friend's mind are not in this direction. It is evident he sees every where defenceless patients suffering from nameless ailments, or "ill of the 